\title{
Powder interlayer bonding of titanium alloys: Ti-6AI-2Sn-4Zr-6Mo and Ti-6Al-4V
}

\author{
P. Davies ${ }^{1} \cdot$ A. Johal ${ }^{1} \cdot$ H. Davies ${ }^{1} \cdot$ S. Marchisio ${ }^{2}$
}

Received: 23 October 2018 / Accepted: 11 February 2019 / Published online: 21 March 2019

(C) The Author(s) 2019

\begin{abstract}
This study introduces powder interlayer bonding (PIB) as a novel joining technique, for the high integrity repair of components, fashioned from two titanium alloys commonly employed in the aerospace industry. The PIB technique in this study utilised a metallic powder interlayer between the two faying surfaces. Heating was provided via induction to create a bond in an inert atmosphere. The PIB technique proved capable of producing high integrity bonds in both Ti-6Al-4V and Ti-6Al-2Sn-4Zr-6Mo. A reduction of less than $10 \%$ in strength is seen for bonds created with both alloys. The deficit seen in ductility for the alloys was deemed acceptable for the industrial applications considered.
\end{abstract}

Keywords Powder interlayer bonding (PIB) · Ti-6-4 · Ti-6-2-4-6 · Titanium powder

\section{Introduction}

Titanium alloys are integral to the efficient operation of modern gas turbines. Since their inception in the 1950s, titanium alloys have been widely utilised in the aerospace industry. These alloys can account for approximately $30 \%$ of the weight of a modern engine [1]. The $\alpha+\beta$ alloys Ti-6Al-4V (Ti-6-4) and Ti-6Al-2Sn-4Zr-6Mo (Ti-6-2-4-6) are two such materials that can be found in numerous locations throughout the gas turbine. These alloys can be produced via traditional processes such as forging and casting and can be heat treated to achieve the mechanical properties required for service. Ti-6-4 is typically found in the fan and compressor sections where it is used for both rotating and structural components [2], while Ti-6-24-6 is used for rotating components in the compressor stages of the gas turbine.

The mechanical properties of these titanium alloys are strongly linked to their microstructures which are controlled by their thermomechanical processing history [3]. Thermomechanical processes such as solution heat treatment,

P. Davies

p.d.davies@swansea.ac.uk

1 Institute of Structural Materials, College of Engineering, Swansea University, Bay Campus, Fabian Way, Swansea SA1 8EN, UK

2 Rolls-Royce Plc, PO Box 31, Derby DE24 8BJ, UK deformation and annealing can create a variety of microstructures, which are often described by the morphology of the $\alpha+$ $\beta$ phases. These can range from the lamellar microstructure which develops during cooling from the $\beta$ phase field, to the equiaxed structure, which develops through a recrystallisation process. The beta transus $\left(\beta_{T}\right)$ is a key parameter in the processing of titanium alloys as it separates the $\beta$ phase field from the $\alpha+\beta$ phase field [4].

Ti-6-4 is the most extensively used titanium alloy due to its excellent balance of mechanical properties at ambient temperatures, namely good strength and fatigue properties, and is commonly used to fabricate wide chord fan blades and discs [5] in the gas turbine. The alloy has been shown to have a UTS of $\sim 1050 \mathrm{MPa}$ [6] and a fatigue strength of $500 \mathrm{MPa}$ at $10^{7} \mathrm{cy}-$ cles at room temperature [7]. The alloy is heat treatable with a reported $B_{T}$ of $996{ }^{\circ} \mathrm{C} \pm 14{ }^{\circ} \mathrm{C}$ [7]. Aluminium is present at $6 \mathrm{wt} \%$ as an $\alpha$-stabiliser, strengthening the $\alpha$ phase via solid solution strengthening. The alloy contains $4 \mathrm{wt} \%$ vanadium as a $\beta$-stabiliser, this exceeds the solubility limit of the $\alpha$ phase at all temperatures, allowing a limited amount of $\beta$ to be retained at room temperature.

Ti-6-2-4-6 is primarily used as a disk and blade material due to its superior fatigue strength and toughness properties at elevated temperatures [8]. The alloy is often $\beta$-forged to improve fatigue crack growth and fracture toughness properties by inhibiting the growth of continuous grain boundary $\alpha$ as this can reduce fatigue strength and ductility [9]. $\beta$-forging promotes the growth of discontinuous, acicular $\alpha$ throughout 
the grain rather than at grain boundaries, which improves fatigue properties of the alloy. UTS values of approximately $1200 \mathrm{MPa}$ and elongations of $7 \%$ can be achieved in $\beta$-forged Ti-6-2-4-6. $\beta$-forging the alloy can increase fracture toughness to above $50 \mathrm{MPa} \mathrm{m}^{1 / 2}[10]$. The alloying elements within Ti6-2-4-6 include 6\%wt aluminium, $2 \%$ wt tin, $4 \%$ wt zirconium and $6 \%$ wt molybdenum with a reported $\beta_{T}$ of $935^{\circ} \mathrm{C}$ [11]. Aluminium is the predominant $\alpha$-stabiliser within the alloy and strengthens via solid solution strengthening, whereas molybdenum is isomorphic with titanium and forms a continuous solid solution with the $\beta$ allotrope of titanium, increasing the response of the alloy with regard to heat treatments. Tin and zirconium are both classed as $\alpha$-stabilising elements. This is due to zirconium's chemical similarity to titanium, and tin's ability to replace aluminium in the hexagonal ordered $\alpha_{2}$ phase [12].

Gas turbine component designs are continuously developing with more complex parts being introduced in to service. Along with increased performance there can be drawbacks that come with implementing complex geometrical components, such as an increased difficulty in repairing these components.

The ability to repair engine components provides engine manufacturers with a significant opportunity to reduce costs through reduced material replacement and a reduction in time off wing. Some of these structures may be large scale, which offer both challenges and opportunities for repair. Component geometry must be retained post repair while adjacent temperature sensitive regions may need to be protected. Advanced materials also provide challenges in repair where higher integrity material properties are required. Component replacement has a considerable effect on costs, accounting for up to $70 \%$ of engine maintenance costs [13]. Examples of joining methods that may be used as repair processes for titanium alloys include fusion welding techniques such as tungsten inert gas (TIG) welding, plasma arc (PA) welding, laser beam (LB) welding and electron beam (EB) welding [14]. These processes melt and re-solidify the base material to produce a weld autogenously or by utilising filler material; the weld region is referred to as a fusion zone (FZ). The high temperatures involved also produce a heat affected zone (HAZ) adjacent to the FZ, where the localised temperature exceeds the $\beta_{T}$ of the material. As a result, the FZ and part of the HAZ develop transformed microstructures [12], whose grains may be far larger than those of the base material [15]. Residual stresses and defects such as porosity are also a consequence of these processes which can affect mechanical properties. The resulting mechanical properties of these regions can also differ from the base material, ductility being one example that can degrade when base alloy strength increases [16].

Successful welding of titanium alloys is complicated by its inherent affinity for oxygen, nitrogen, carbon and hydrogen at the temperatures witnessed during welding operations.
Therefore, the processes previously mentioned rely on shielding the weld zone with inert gases such as argon or in the case of EB welding, by performing the operation in a vacuum [17]. For successful welds to be produced cleanliness is critical, where surfaces, fixtures and fittings must be cleaned to avoid contamination.

TIG welding is a widely used process capable of producing high quality, economical welds in titanium alloys of thin section sizes up to a few millimetres thick $[18,19]$. It is a robust process, where alignment is not as critical as other joining techniques due to the wide fusion and heat affected zones created. However, due to the high heat input, deformation can be a major concern [20]. Due to its constricted arc, PA welding offers improved arc stability and lower workpiece distortion over TIG welding. Wide fusion and heat affected zones again provide a robustness to the process but these advantages come at far higher equipment costs [18]. LB welding is a power beam welding process providing a concentrated heat source with minimal distortion. The resulting microstructures seen at the FZ are finer than those seen with TIG welding [21], with changes being limited to narrow fusion and heat affected zones $[22,23]$. Weld conditions must be accurately controlled, and positioning is critical due to the narrow diameter of the beam. High costs compared to other joining processes inhibit extensive use. EB welding is an alternative for LB welding and can be used to join thicker sections due to its higher penetrating power. Similarly, to LB welding it offers narrow HAZ's with low distortion. Very high-quality joints can be achieved with tensile properties of the weld approaching those of the base material [24]. Again, control and positioning are key with costs being even more prohibitive than LB welding.

Diffusion bonding (DB) is another process that has been utilised in the gas turbine to join titanium alloys [6]. It has been successfully used to produce wide chord fan blades found on Trent engines [25]. As with all welding operations cleanliness is critical for successful DB to be performed, with the wide chord fan blades being produced in a clean room environment. DB is an expensive and complicated process and does not lend itself well to the repair process; where issues such as asperities between bonding surfaces can lead to excessive porosity. Recently, interlayers have been utilised to facilitate the joining of dissimilar alloys. Niobium interlayers have been used in conjunction with laser welding to join NiTi to Ti-6-4 [26], where they promoted crack free welds and prevented the formation of brittle intermetallics. A nickelbased superalloy and TiAl alloys have been successfully laser welded by utilising vanadium and copper composite interlayers [27] — the interlayer again helping to reduce the formation of brittle intermetallics and improving joint strength. Interlayers have also been used in combination with electron beam welding, where niobium and copper 
interlayers have been used to facilitate the bonding of titanium and kovar alloys [28].

The present investigation introduces powder interlayer bonding (PIB) as a novel joining technique providing high integrity joints at relatively low cost, while providing opportunities to salvage otherwise redundant gas turbine components [14]. In this study, the PIB technique utilises a metallic powder interlayer between the two faying surfaces, eliminating surface asperities and reducing the dependency of the bonding process on smooth surface finish. The process utilises inert gas shielding to protect the FZ from oxidation during bonding. Heating in the example offered in this work is provided by induction, which is an efficient method of heating metals such as titanium. The technique provides several advantages over the previously mentioned joining practices such as localised heating, narrow fusion zone, reduced residual stress in the bond region and portability, which can be a major advantage for repair. PIB has the potential to compete against these more mature techniques, offering a method of joining that is applicable to a variety of aerospace alloys.

\section{Experimental procedures}

All materials investigated in this work were supplied by RollsRoyce Plc in the form of $10-\mathrm{mm}$ diameter bars. The asreceived (AR) Ti-6-4 specimens were taken from a section of cross-rolled plate that underwent rolling in the $\alpha+\beta$ region to produce plate $\sim 13 \mathrm{~mm}$ thick. The Ti-6-2-4-6 AR material studied was taken from a forging that had been $\beta$-forged, then solution treated for up to $2 \mathrm{~h}$ at approximately $870{ }^{\circ} \mathrm{C}$ before being aged at approximately $600{ }^{\circ} \mathrm{C}$ for $8 \mathrm{~h}$.

The gas atomised Ti-6-4 (Fig. 1a) and Ti-6-2-4-6 (Fig. 1b) powders used in this study were supplied by LPW Technology Ltd., with powder particles having a diameter between 15 and $45 \mu \mathrm{m}$ and $25-53 \mu \mathrm{m}$ respectively. Powder interlayers were created by combining either Ti-6-4 or Ti-6-2-4-6 powder with cellulose powder, glycerol and deionised water to create a paste. The powder paste was then applied to the surface of one of the faying surfaces to a thickness no greater than
$400 \mu \mathrm{m}$, utilising a measuring jig to ensure the paste thickness and to prevent powder loss. Prior to applying paste and attaching thermocouples, both parts were ultrasonically cleaned in industrial acetone for $30 \mathrm{~min}$.

The two parts (including one with an interlayer) to be bonded were attached to the rods of a servo-hydraulic rig via collets. The faying surfaces were then brought in to contact. The bonding procedure was performed in an argon chamber, shielding the two parts from the local environment. The bond regions of both alloys were initially heated by a water-cooled induction coil to $900{ }^{\circ} \mathrm{C}$, at a heating rate of approximately $6{ }^{\circ} \mathrm{C} / \mathrm{s}$. In order not to exceed the bonding temperature, a second heating rate of $0.5^{\circ} \mathrm{C} / \mathrm{s}$ was then employed to achieve the final temperatures in the individual alloys $\alpha+\beta$ regions. The bonding temperatures were then held $\left( \pm 5^{\circ} \mathrm{C}\right)$ for $60 \mathrm{~min}$. After bonding was completed, the joined specimens were aircooled to room temperature.

Temperature was measured by type $\mathrm{N}$ thermocouples welded in place within $1 \mathrm{~mm}$ of the faying surface and connected to a calibrated Fluke 54 II thermometer. An initial stress no greater than $50 \mathrm{MPa}$ was applied across the bond line for $60 \mathrm{~min}$.

To facilitate metallographic analysis, the specimens were mounted in conductive Bakelite. Specimens were then prepared via a standard grinding and polishing procedure concluding with a final polish using a non-crystallising colloidal silica solution $(0.04 \mu \mathrm{m})$. The samples were etched with Krolls reagent for approximately $10 \mathrm{~s}$ before being thoroughly rinsed under running water. The microstructural and microtextural characterisation of the individual alloys was performed using a Hitachi SU3500 scanning electron microscope (SEM) equipped with electron backscatter diffraction (EBSD) and energy dispersive spectroscopy (EDS) facilities. The mean linear intercept (M.L.I.) method was used to calculate the average grain size of the materials. The approximate volume of retained beta phase was determined manually using Photoshop software. Retained beta was identified in several images, allowing the volume fraction to be calculated from the total area recorded. To obtain a value for the total amount of porosity through a bond, a bonded specimen was sectioned
Fig. 1 Powders used during bonding process a Ti-6-4 $\mathbf{b}$ and Ti-6-2-4-6
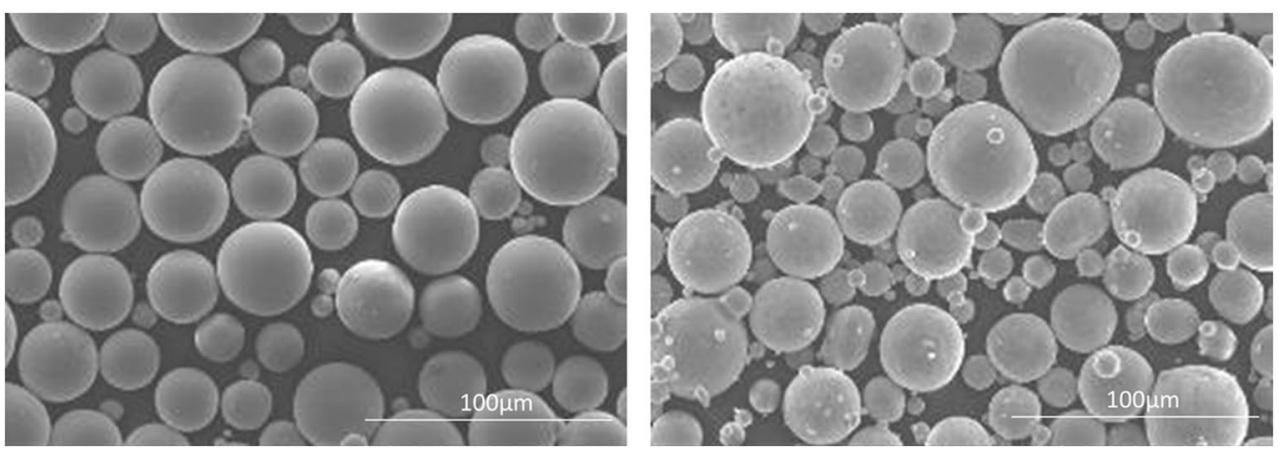

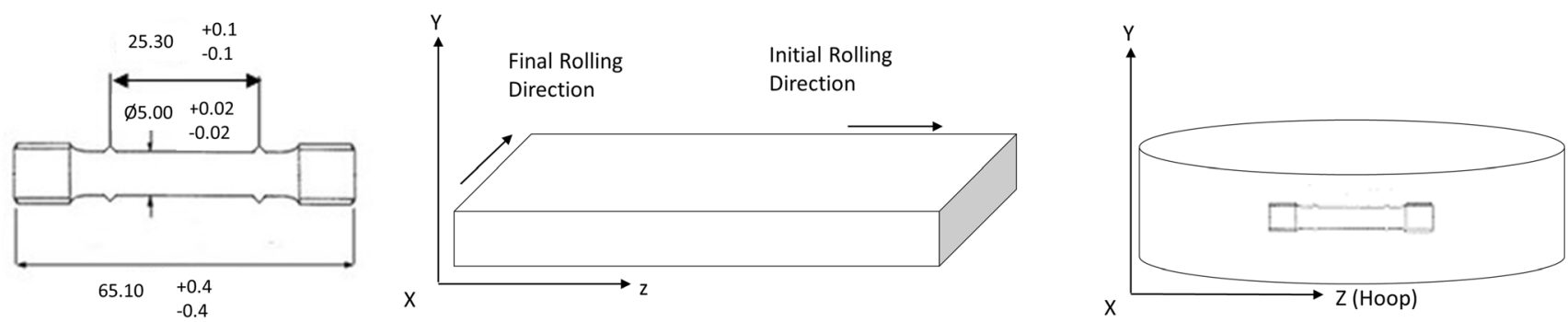

Fig. 2 Illustration of tensile specimen used and orientation taken from Ti-6-4 plate and Ti-6-2-4-6 forging

and prepared for microstructural analysis. A stitch of images was obtained across the length of the bond line at a fixed magnification. Using the 'threshold' function on ImageJ software, the images were adjusted so that the pores were highlighted using the sliding bar. Once the highlighted pores have been selected, the 'measure' function is used to calculate the percentage and total area of the pores.

Pipped cylindrical tensile specimens, as shown in Fig. 2a, were machined from the bonded test pieces for subsequent mechanical testing. The orientation these specimens were removed from the original material is shown in Fig. 2b. Tensile tests were performed at room temperature in accordance with BS EN 2002-1:2005. This standard is a common practise amongst the engineering industry and allows the use of dual strain rates. A relatively low strain rate (3E-5) was employed during the elastic regime and onwards through yield followed by a more rapid rate (2E-3) to induce failure. The transition between the two applied strain rates induces an obvious step increase in the induced stress response. The nominal values of strain quoted in this paper were measured via actuator displacement. Once failed, specimen halves were deliberately not brought into contact as a method of measuring elongation to failure so as not to damage the key features on the fracture surfaces.

\section{Results and discussion}

\subsection{Microstructures of the original materials}

The original microstructures of the Ti-6-4 and Ti-6-2-4-6 materials are shown in Figs. 3 a-c. The Ti-6-4 material was found to have an essentially equiaxed structure, with an average $\alpha_{p}$ grain size of $\sim 15 \mu \mathrm{m}$ and $\sim 5 \%$ retained $\beta$ located at the triple points of the $\alpha_{p}$ grains, which is typical of rolled Ti-6-4 plate [6]. The Ti-6-2-4-6 material exhibits a microstructure composing of prior $\beta$ grains with an average grain size of $\sim 300 \mu \mathrm{m}$,
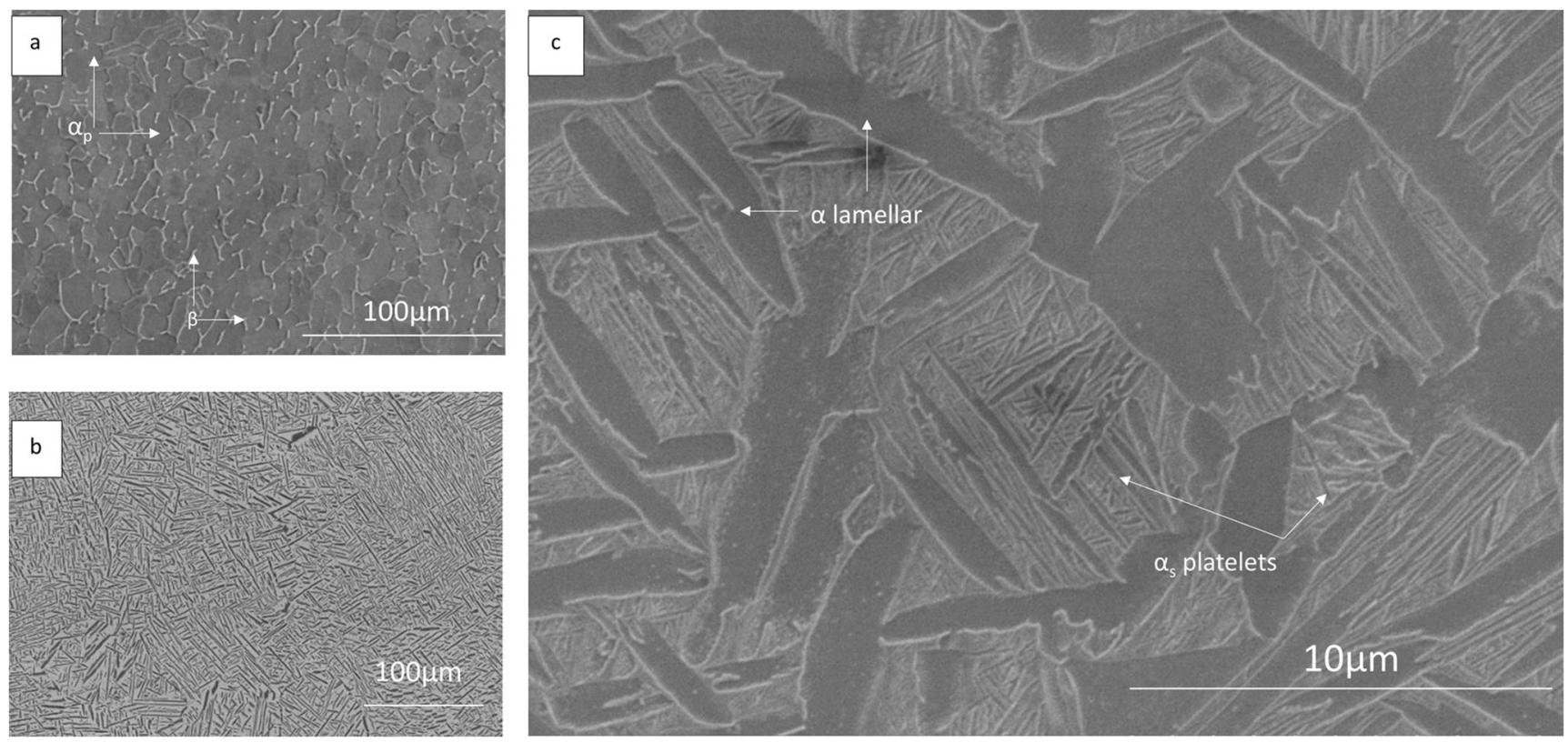

Fig. 3 Microstructure of a Ti-6-4 material, b Ti-6-2-4-6 and c high magnification of Ti-6-2-4-6 
with fine $\alpha$ lamellar with an average width of $1 \mu \mathrm{m}$ retained in a $\beta$ matrix. The $\beta$ matrix was found to contain colonies of fine secondary $\alpha$ platelets $50-200 \mathrm{~nm}$ in width as illustrated in Fig. 3 c. The ageing process applied results in very little grain boundary alpha $\left(\alpha_{\mathrm{GB}}\right)$ in the microstructure.

In the AR condition the Ti-6-4 plate was found to have a characteristic cross-rolled texture with strong $\{0002\}$ basal components aligned to both rolling directions. A relatively high-texture intensity 13.03 times random was discovered, with evidence of large macro zones present in the material, illustrated in the IPF map in Fig. 4 a. The Ti6-2-4-6 alloy was found to have $\alpha$ and $\beta$ texture intensities of 5.52 and 3.36 times random respectively as illustrated by the pole figures in Fig. 4 b.

\subsection{Macro inspection of PIB sample}

During the bonding process, a certain amount of deformation or upset was seen between both the original pieces. The degree of upset is the change in overall length resulting from the load applied in the longitudinal axis as described in Eq. 1 as follows:

$\varepsilon_{\rho}=\frac{l_{o}-l_{f}}{l_{o}}$

where $\varepsilon_{\rho}$ is the degree of upset, $l_{o}$ and $l_{f}$ the original and final length respectively. Typically, the Ti- $6-4$ bonds see $\sim 6 \%$ upset over the length and $\sim 34 \%$ increase in cross-sectional area. A
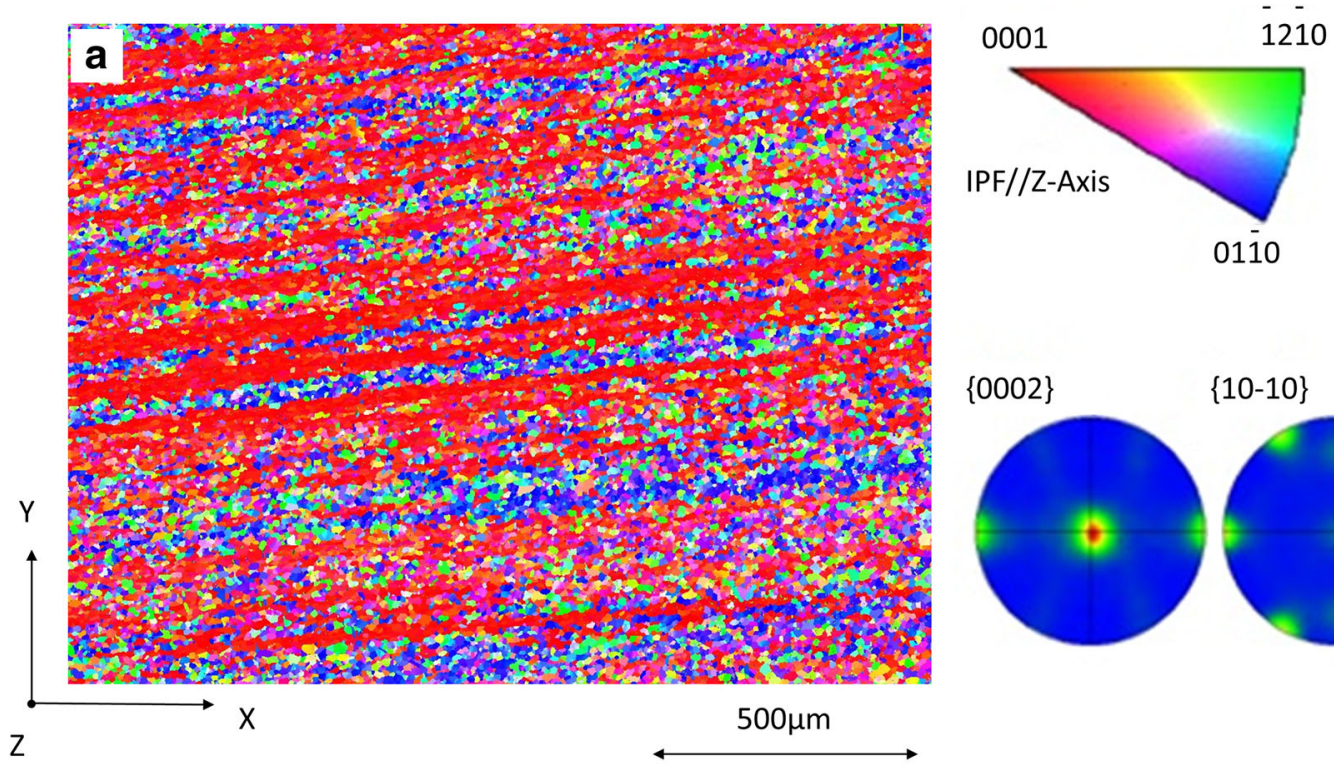

1210

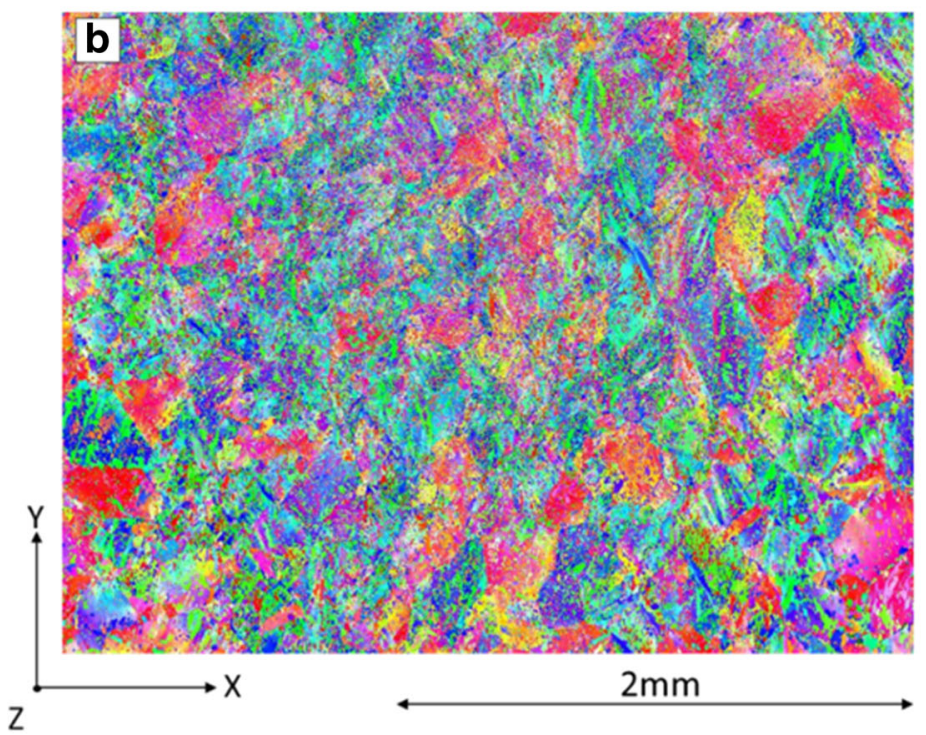

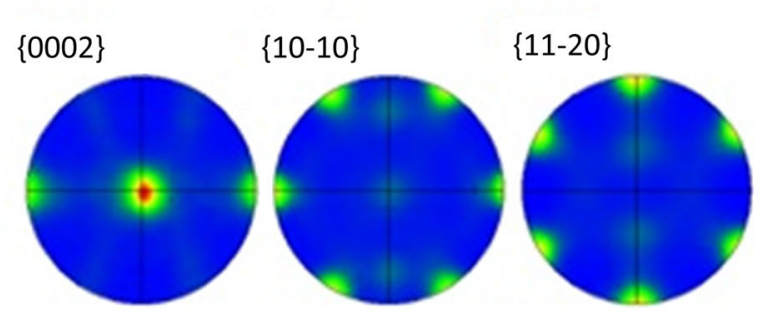

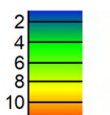

$\operatorname{Max}=13.03$

$\{11-20\}$

0001

$\overline{12} 10$

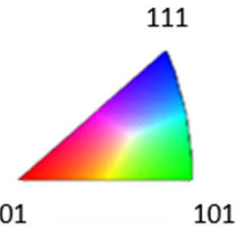

\{0002\}

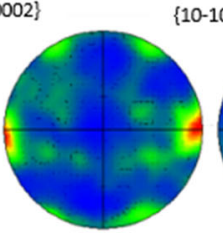

(10-10\} $\{11-20\}$
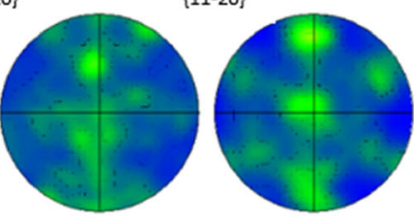

$\operatorname{Min}=0$

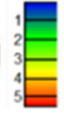

$\operatorname{Max}=5.52$

$\{111\}$

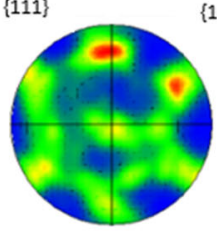

$\{101\}$

$\{001\}$

Cubic
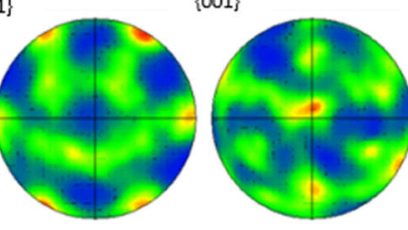

Min $=0$

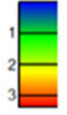

$\operatorname{Max}=3.36$

Fig. 4 EBSD-derived IPF//Z pole figures for a Ti-6-4 alloy and $\mathbf{b}$ Ti-6-2-4-6 in the as-received condition 


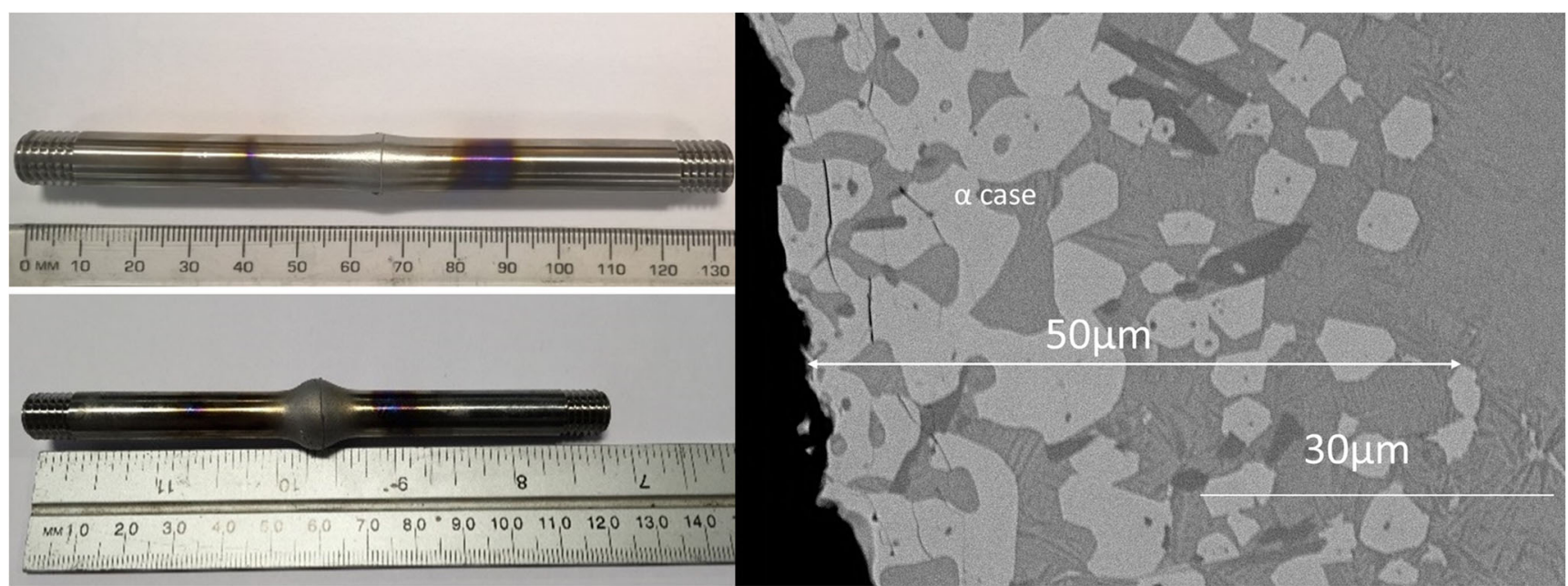

Fig. 5 Examples of completed bonds for a Ti-6-2-4-6, b Ti-6-4 and $\mathbf{c}$ depth of $\alpha$ case formation in proximity of bond line for Ti-6-4

lesser amount of deformation was seen in the Ti-6-2-4-6 bonds with $\sim 3 \%$ reduction in total length and $\sim 28 \%$ increase in cross-sectional area. Examples of completed bonds and the resultant deformation are illustrated in Figs. $5 \mathrm{a}$ and $\mathrm{b}$.

There appears to be a limited amount of oxidation on the surface in the proximity of the bond line of both specimens; this is unsurprising as Ti-6-4 is known to dissolve any oxide on its surface at temperatures above $925^{\circ} \mathrm{C}$ [7]. There are, however, oxide rings visible $\sim 20 \mathrm{~mm}$ away from the bond line, due to the lower temperatures experienced in these regions.

Figure $5 \mathrm{c}$ shows that both alloys were seen to develop a relatively uniform layer of $\alpha$ case at the surface post bonding; this was measured as $\sim 40-50 \mu \mathrm{m}$. This brittle $\alpha$ case layer can be easily cracked on loading and can be detrimental to mechanical properties such as LCF performance. Such areas would need to be dressed away during any repair process before PIB repairs were put back into service.

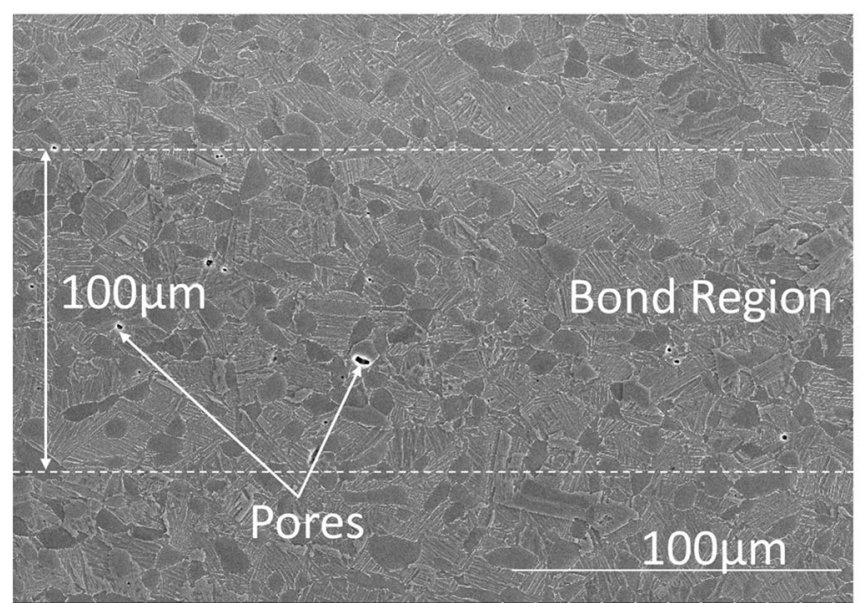

Fig. 6 Microstructure across the bond line of bonded a Ti-6-4 b Ti-6-2-4-6

\subsection{Microstructure of the bond region}

Examples of the microstructures across the bond line of the PIB Ti-6-4 and Ti-6-2-4-6 materials are illustrated in Figs. 6 a and b. Figure 6 a clearly demonstrates that the Ti-6-4 bonding cycle produces a bi-modal or duplex microstructure with equiaxed $\alpha_{p}$ grains in a transformed $\beta$ matrix throughout the bond region. The alloy was found to consist of $\sim 32 \% \alpha_{p}$ volume fraction with an average $\alpha_{p}$ grain size of approximately $16 \mu \mathrm{m}$. The bond line is approximately $100 \mu \mathrm{m}$ thick through the centre region of the Ti-6-4 bond. A limited amount of porosity is seen throughout the bond line, with maximum pore size found to be below $10 \mu \mathrm{m}$ in diameter.

When looking at the microstructure for bonded Ti-6-24-6 (Fig. 6b), the bond line has a thickness of $\sim 180 \mu \mathrm{m}$ through the centre region. Some porosity can be found within the interlayer region or at the interface between 
Fig. 7 Illustration of the typical porosity distribution through a $\mathrm{Ti}-$ 6-4 bond

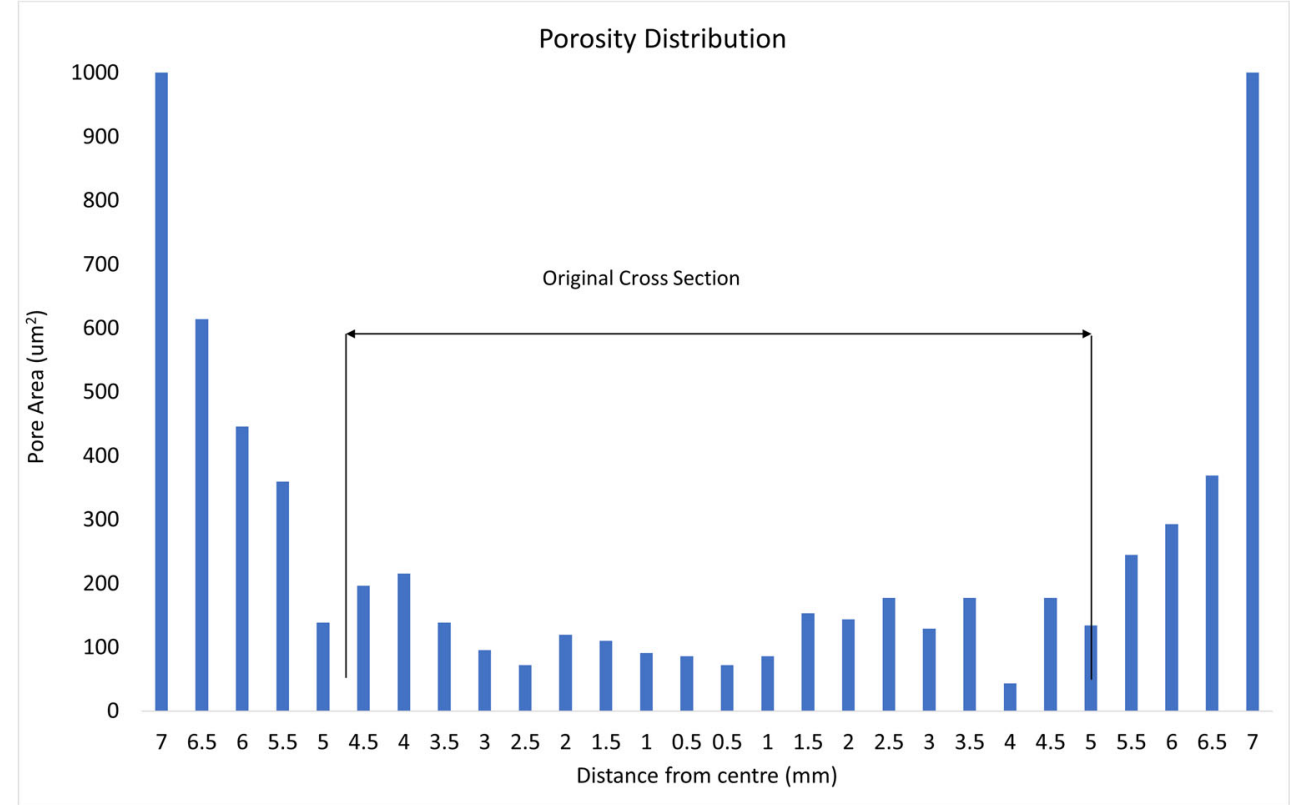

the interlayer and the base material, as with the Ti-6-4 alloy these pores were found to be below $10 \mu \mathrm{m}$ in diameter. As can be seen in Figs. 6a and b, there is a significant difference in the thickness of the bond line between both alloys. The main reason for the disparity in this example is the Ti-6-2-4-6 alloy having an initial interlayer approximately twice the thickness of the Ti-6-4 alloy. Using the method described in Section 2, the total porosity retained through a single plane of the bond region of the Ti-6-4 alloy was found to be approximately $7300 \mu^{2}$. Figure 7 illustrates that a significant amount of the remaining porosity is located within the upset region of the bond formed. As previously mentioned, repaired components would be dressed before being put back into service, thus removing this upset region and in the case of the Ti-6-4 alloy $\sim 65 \%$ of the retained porosity.

\subsection{The bonding process}

Transforming the powder into a solid form occurs through a solid-state sintering process. The process utilises thermal energy combined with the applied force to consolidate and densify the powder. The process is driven by reducing the total interfacial energy, as expressed by Eq. 2 .

$\Delta(\gamma A)=\Delta \gamma A+\gamma \Delta A$

where $\gamma A$ is the total interfacial energy, $\gamma$ is the specific surface (interface) energy and $A$ the total surface (interface) area. The reduction in interfacial energy is a result of densification and
Fig. 8 Illustration of a powder densification curve for a sintering/ bonding cycle for Ti-6-2-4-6 [30]
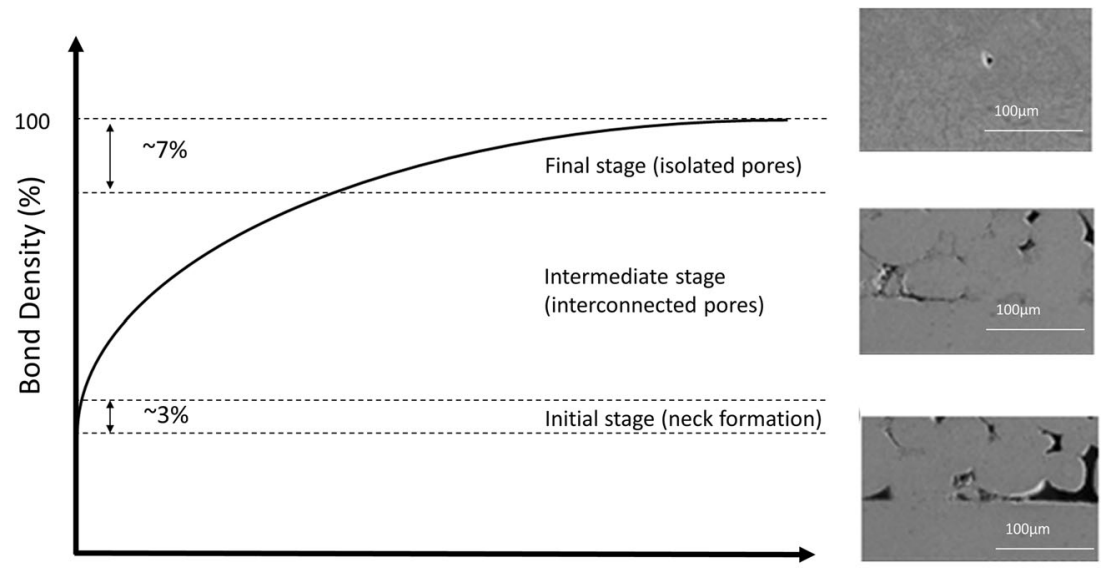

Bonding Time 


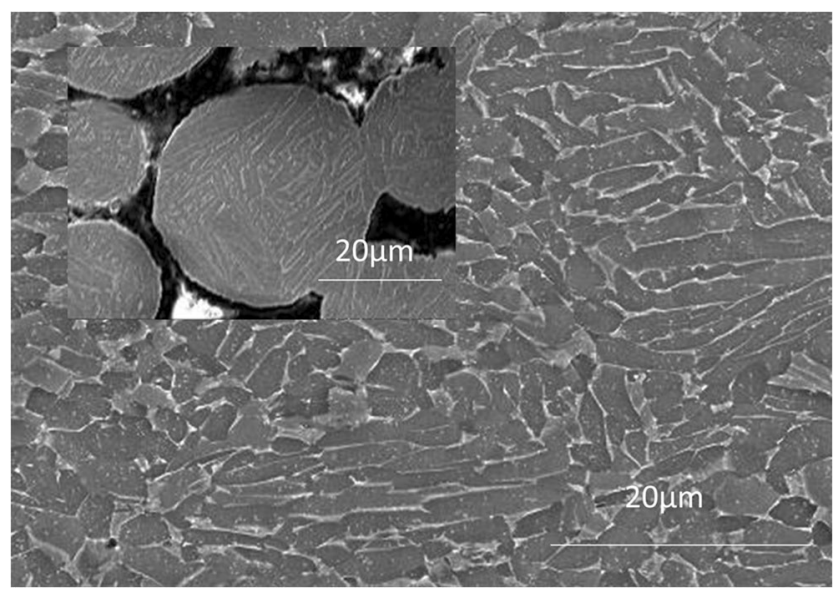

Fig. 9 Realignment of powder lath structure perpendicular to the loading direction for a Ti-6-4 bond

the change in interfacial area is due to grain coarsening which is the basis of sintering. For solid-state sintering, $=\Delta \gamma$ is related to the replacement of solid/vapour interfaces (surface) by solid/solid interfaces [29].

The bonding cycle shares a commonality with the solid-state sintering cycle as illustrated in Fig. 8, where the bonding process can be viewed as three associated phases: the initial, intermediate and final phase. During the initial phase localised bonding occurs between adjacent powders (grains) via the formation of necks with high curvatures, and a small amount of plastic deformation is seen, this may be below 5\%, as seen in a sintering cycle. For bonding to proceed between particles, material must be transported from the particle to the neck region via diffusion (vacancy migration). Surface stresses at the neck result in a higher concentration of vacancies (absence of atom or molecule) due to the regions nonuniform curvature when compared to the surface of the particle away from this region. At bonding temperatures, vacancies can diffuse away from the neck through the powder particle via volume diffusion or along the surface of the powder via surface diffusion [30]. The net result of this diffusion of vacancies is a flow of material in the opposite direction. Continued transport of material to the neck region facilitates the continued growth of the necks and pore shrinkage as powder bonding enters the intermediate phase.

The intermediate phase of bonding is characterised by the pores beginning to round. Most of the deformation and densification of the powders occurs during this intermediate phase of the process; it has been reported that up to $93 \%$ of the relative density happens before isolation of the pores during a sintering cycle [29]. During the early stages of densification, plastic deformation can be a major factor in the densification of the powders. However, as the total surface area of the powders continue to shrink, deformation slows until finally stopping. The deformation witnessed during this phase includes a realignment of the powder lath structure, becoming generally perpendicular to the loading direction as shown in Fig. 9. Sufficient stored energy is introduced via the deformation, enabling recrystallisation of the $\alpha+\beta$ phases during the final phase. The final phase involves the subsequent final densification of the bond and the elimination of isolated pores, via continued pore rounding and general pore shrinkage. This is the most time-consuming phase, taking up most of the bonding time as illustrated in Fig. 8.

Together with time, bonding temperature and applied force are integral to final powder consolidation; increases in temperature intensify the driving force for densification and greatly affect process kinetics due to the exponential relationship between temperature and atomic diffusion. Controlling temperature is critical during bonding; for example, exceeding the $\beta_{T}$ of the alloys would have a fundamental effect on the final microstructures; degrading mechanical properties such as LCF performance. The force applied, especially during the initial stages of the bonding cycle, plays a significant role in successful bonds. Too high a load can result in excessive deformation and buckling of the specimens, if too low a force is applied, then insufficient plastic deformation of the powder occurs. Increasing the bonding time was found to
Fig. 10 Examples of partial powder collapse for Ti-6-4 alloy due to $\mathbf{a}$ insufficient force $\mathbf{b}$ insufficient temperature
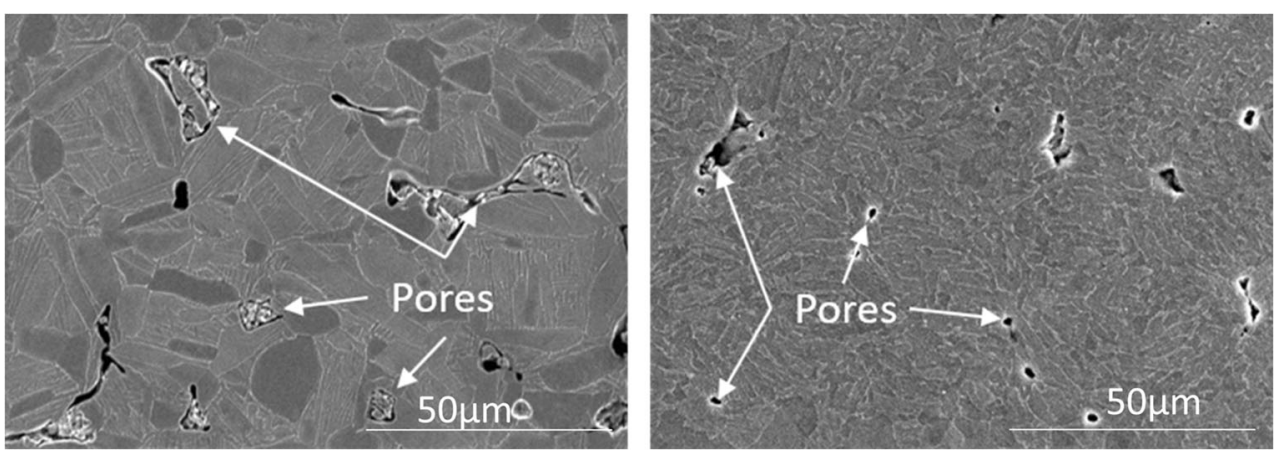
Fig. 11 Stress strain curves for Ti-6-4, Ti-6-2-4-6 AR materials and PIB bonds

Fig. 12 EBSD-derived pole figures, IPF//X through bond regions for a Ti-6-4 alloy and $\mathbf{b}$ Ti-6-2-4-6 alloy

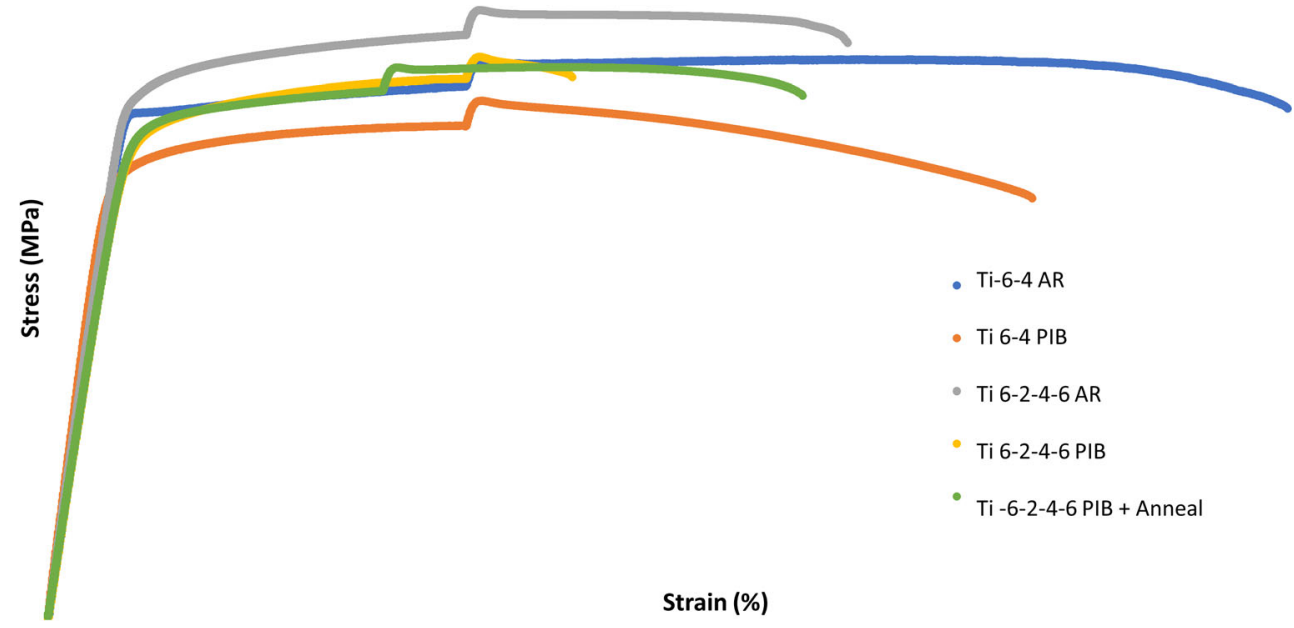

a $\{0002\}$

$\{10-10\}$

$\{11-20\}$
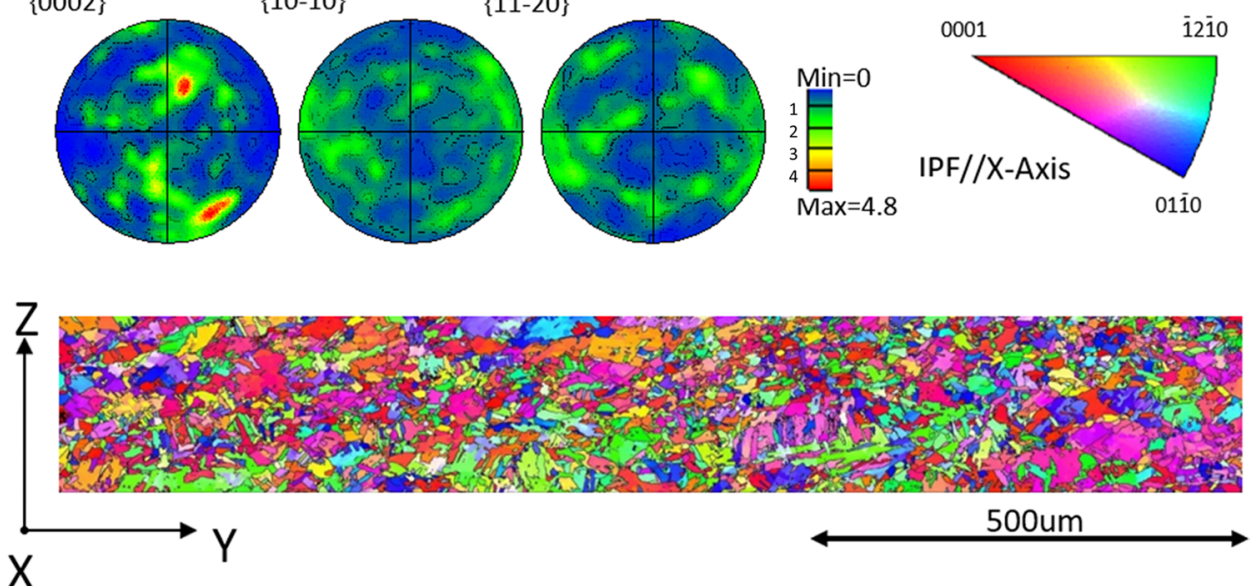

b Hexagonal

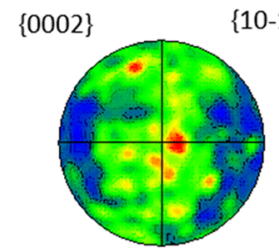

10-10\}

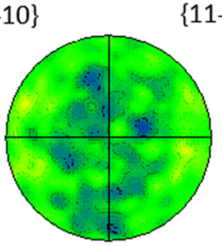

\{11-20\}

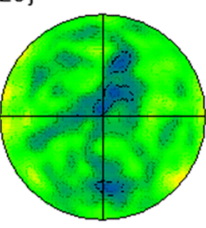

Min $=0$
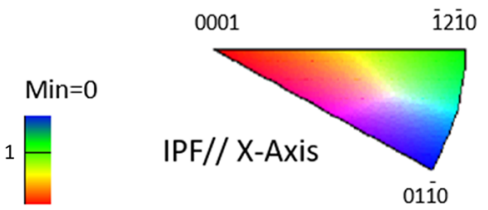

$\operatorname{Max}=2.33$
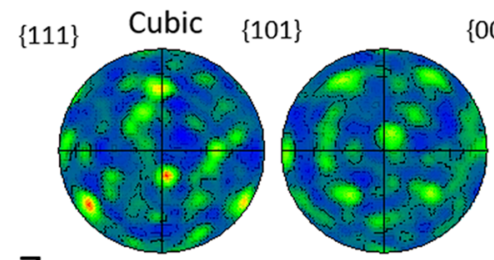

$\{001\}$
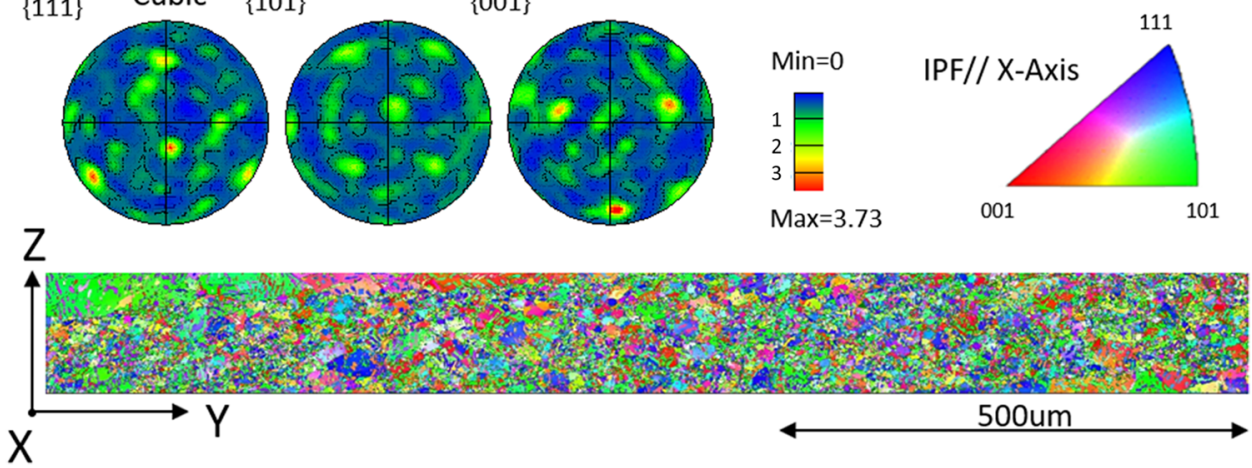


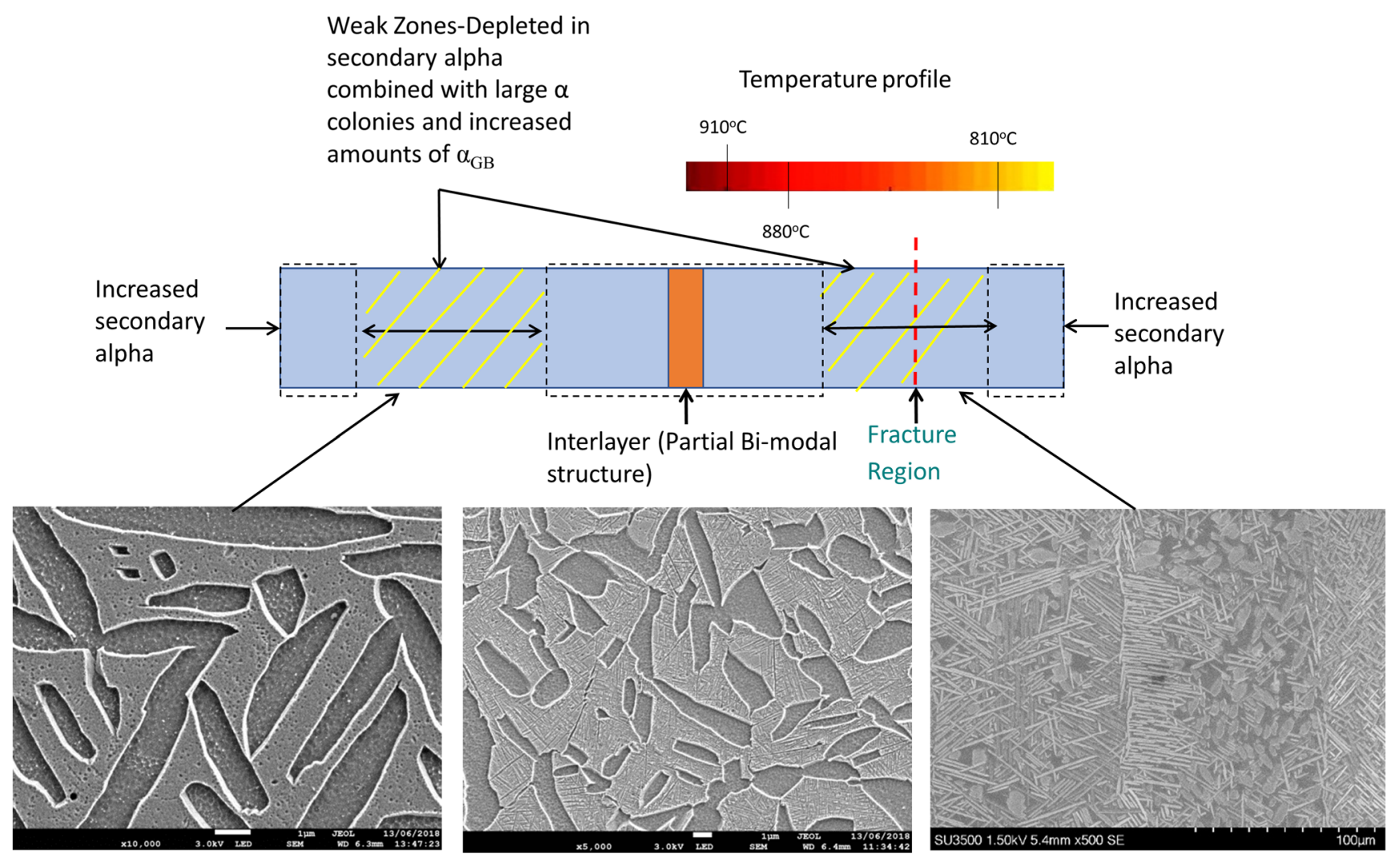

Fig. 13 Schematic representation of a weak zone created in a Ti-6-2-4-6 PIB sample due to the lack of fine secondary $\alpha$ platelets

improve powder densification; however, diminishing improvements are realised with increasing time. Examples of insufficient force and temperature are illustrated in Figs. $10 \mathrm{a}$ and $\mathrm{b}$, where partial powder collapse results in excessive pore size which cannot be eliminated during the final phase.

\subsection{Tensile properties}

The tensile curves for the bonds created in this study are illustrated in Fig. 11. These clearly demonstrate that excellent properties are maintained for both alloys utilising the PIB process. On analysis the Ti-6-4 PIB specimens fractured in the bond region, while the Ti-6-2-4-6 PIB specimens fractured $\sim 7 \mathrm{~mm}$ remote of the bond region. Reductions in strength of approximately 10 and $8 \%$ are seen in the Ti-6-4 and Ti-6-2-46 alloys respectively. To achieve a further improvement in properties for Ti-6-2-4-6 an anneal treatment of $640{ }^{\circ} \mathrm{C}$ for $2 \mathrm{~h}$ was added as a post process heat treatment. The result of the anneal, shown in Fig. 11, displays an improvement in ductility with UTS remaining largely unaffected.

It is suggested that the reduction in strength of the Ti-6-4 PIB specimens can be largely explained by the different textures found in the Ti-6-4 AR and PIB specimens. There are strong texture components found in the Ti-6-4 AR material as shown in Fig. 4 a. The AR material was tested in the direction with the strongest texture component of approximately 13 times random. Testing in this direction can be compared to testing in the transverse direction of unidirectional rolled material, where it has been shown that reductions of between 5 and $8 \%$ in strength have been seen for Ti-6-4 [31] between the transverse and rolling directions respectively. As illustrated in Fig. 12 a, the recrystallised microstructure through the bond region of a Ti-6-4 PIB specimen has a much weaker texture intensity of approximately five times random. The strongest texture component is approximately $30^{\circ}$ away from typical basal texture, which is generally believed to indicate that recrystallisation has occurred during the process [32]. The Ti-6-4 PIB specimens maintain comparable levels of ductility to the base material; this is not unexpected as it has been shown that texture does not greatly affect ductility [33]. The debit in strength and ductility seen in the Ti-6-2-4-6 PIB specimens is more complex than that of the Ti-6-4 alloy. Texture does not appear to be a major factor with the Ti-6-2-4-6 alloy as illustrated in Fig. 12 b, where a slight decrease in intensity is seen for the $\alpha$ phase when compared to the AR material.

It is suggested that the bonding cycle has created a weak zone in the region of fracture as illustrated in Fig. 13. Figure. 13 shows that the bonding cycle has produced a microstructure in the bond region with bi-modal characteristics; containing globular $\alpha_{p}$ with an average grain size of $\sim 6 \mu \mathrm{m}$ and coarse $\alpha$ laths in a matrix of small transformed $\beta$ grains 
Fig. 14 Examples of fracture mode in Ti-6-4 alloy
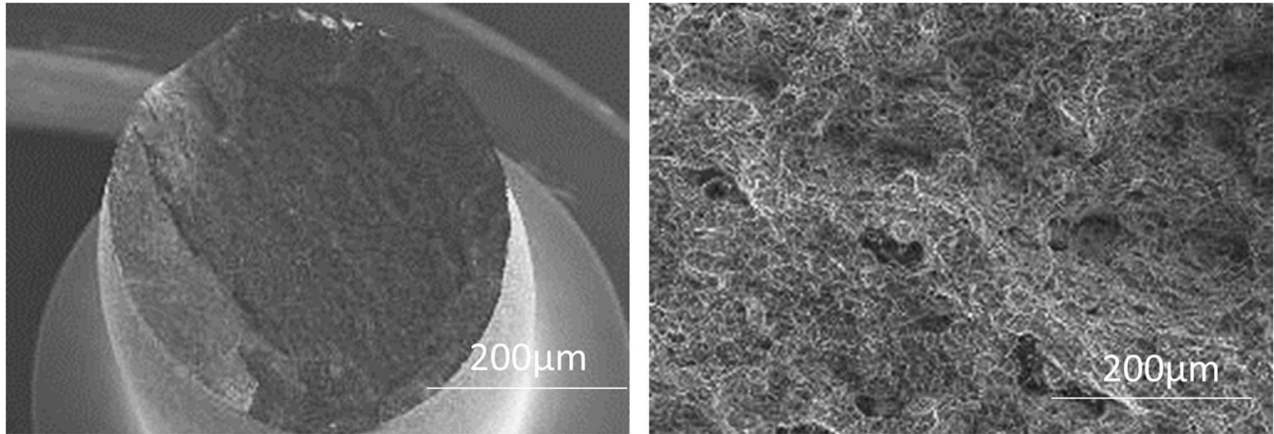

through the bond region of the Ti-6-2-4-6 specimen. However, insufficient dislocation density has been introduced during deformation to allow complete recrystallisation to occur, limiting the volume of $\alpha_{p}$ present in the microstructure. Figure 13 also shows the microstructure of the bonded Ti-6-2-4-6 specimen in the region of fracture, where there is no secondary $\alpha$ present in the $\beta$ grains, resulting in a weakness in this area. Lutjering [34] reported that the precipitation of fine $\alpha$ plates through the $\beta$ phase improved the mechanical properties of $\alpha$ $+\beta$ alloys. A similar effect was reported by Thomas et al. [35] in the Timetal $575 \alpha+\beta$ alloy where fine $\alpha$ plates precipitated in the transformed $\beta$ were thought to be key for strength optimisation. The fine secondary $\alpha$ found in the AR material and the more extreme regions of the bonded samples acts to strengthen the alloy by reducing the effective slip length across the $\alpha$ colonies in these regions. The addition of a post bonding annealing step acts to alleviate this weakening effect seen in Ti-6-2-4-6 by precipitating $\alpha_{s}$ in the fracture region. The tensile result for the annealed sample shows that by increasing the $\alpha_{s}$ in the weakened region, it is possible to achieve elevated properties, especially with regard to ductility. Figure 13 illustrates that an increased amount of $\alpha_{\mathrm{GB}}$ and large $\alpha$ colonies were present in the microstructure in the fracture region, which have both been shown to negatively affect ductility in $\alpha+\beta$ alloys.

A slight reduction is seen in the Young's modulus value for the Ti-6-4 PIB specimen of $\sim 4.5 \%$, while a larger drop of $16.5 \%$ was recorded for the Ti-6-2-4-6 alloy. Although there is a variation in the amount of reduction seen between Ti-6-4 and Ti-6-2-4-6 alloys, the trends are consistent with previously reported results [31]. Analysis of the fracture surfaces of all the bonded samples highlighted that as with the starting materials, the fracture mode of both alloys was found to be ductile in nature, with ductile dimples seen throughout the typical cup and cone fracture surfaces, an example of this is illustrated in Fig. 14.

\section{Conclusions}

This study has investigated the suitability of PIB as a novel joining technique for the high integrity repair of aerospace components fashioned from two titanium alloys commonly employed in the aerospace industry. Microstructural characterisation of the Ti-6-4 and Ti-6-24-6 alloys was performed before and after the bonding cycle. Comparisons have been made between the PIB process and the sintering process to explain this novel technique. Conclusions are presented below:

- Powder interlayer joining (PIB) incorporating a metallic powder interlayer between the two faying surfaces and argon gas shielding has proved successful as a joining technique for the repair of titanium alloy components.

- PIB provides advantages over more mature and currently used joining practices such as localised heating, narrow FZ, low residual stress in the bond region, and the anticipation of portability as the process matures, which can be a major advantage for repair.

- PIB can produce high integrity bonds in Ti-6-4 and Ti-6-24-6. A reduction of only $10 \%$ is witnessed in strength and comparable ductility is recorded when compared to baseline Ti-6-4 material.

- For the Ti-6-2-4-6 material, a strength reduction of only $8 \%$ is seen in the bonded condition. Although a significant reduction is seen in ductility, it has been shown this can be mostly alleviated via the use of post process anneal.

- A significant amount of the remaining pores were found in the upset region of the bond in both alloys, outside of the original gauge. This is important as this region is likely to be removed during post processing. This operation will also remove the resulting alpha case on the surface of the bond region, removing the risk of compromised mechanical properties. 


\section{Future work}

It is believed that PIB is a technique that is applicable to a variety of aerospace alloys. Plans are in place to investigate its suitability for the joining of other advanced materials such as ALM produced titanium and nickel alloys. Although these initial results are very promising, further work into the effect of bonding parameters and interlayers should provide additional improvements in mechanical properties. The effect of different size powders is also to be studied. It is thought reducing powder size may reduce both the maximum size and density of retained porosity post bonding. Actual components will have more complex geometries than those studied here, thought to this will need to be included in further work. Ultimately, the integrity of bonded components will be determined by their fatigue performance, both LCF and HCF testing are planned for both titanium alloys studied in this work.

Open Access This article is distributed under the terms of the Creative Commons Attribution 4.0 International License (http:// creativecommons.org/licenses/by/4.0/), which permits unrestricted use, distribution, and reproduction in any medium, provided you give appropriate credit to the original author(s) and the source, provide a link to the Creative Commons license, and indicate if changes were made.

\section{References}

1. Peters M, Kumpfert J, Ward CH, Leyens C (2003) Titanium alloys for aerospace applications. Adv Eng Mater 5(6):419-427

2. Inagaki I, Tsutomu T, Yoshihisa S, Nozomu A 2014 Application and features of titanium for the aerospace industry

3. Lütjering $G$ (1998) Influence of processing on microstructure and mechanical properties of $(\alpha+\beta)$ titanium alloys. Mater Sci Eng A 243(1-2):32-45

4. Peters CLM, Hemptenmacher J, Kumpfert J, Leyens C (2003) Structure and properties of titanium and titanium alloys. In Titanium and Titanium Alloys Fundamentals and Applications. Wiley-VCH, p. 532

5. Hewitt JS, Davies PD, Thomas MJ, Garratt P, Bache MR (2014) Titanium alloy developments for aeroengine fan systems. Mater Sci Technol 30(15):1919-1924

6. Davies P, Whittaker M, Thomas M (2013) Development of a new alpha/beta titanium alloy for gas turbine aerofoils. In: In materials science and technology conference and exhibition, Montreal. pp. 2975-2982

7. Properties and processing of TIMETAL $6-4$, TIMET brochure, retrieved from www.timet.com/assets/local/documents/ datasheets/alphaandbetaalloys/6-4.pdf

8. Esslinger $\mathbf{J}$ (2003) Titanium in aero engines demands on titanium alloys and processes in aero engines, Proc 10thWorld Conf on Titanium, vol (5). Wiley-VcH Weinheim, Germany, pp. 2845-2852

9. Choda T, Oyama H, Murakami S (2015) Technology for process design of titanium alloy forging. Kobelco Technol Rev 33:460-465

10. Boyer R, Welsch G, Collings E (1994) Materials properties handbook: titanium alloys, 1st ed. ASM international, Materials Park, Ohio.

11. Sauer C, Lutjering G (2001) Influence of $\alpha$ layers at $\beta$ grain boundaries on mechanical properties of Ti-alloys. Materials Science and Engineering A, 319-321:393-397
12. Lütjering G, Williams JC (2007) Titanium, 2nd ed. Springer, Berlin Heidelberg, New York

13. Ackert S (2011) Engine maintenance concepts for financiers. Aircr Monit 2:30

14. Forsdike J (2009) Novel joining and repair of aerospace materials, (Ph.D. Thesis), Swansea University, UK

15. Sundaresan S, Janaki Ram GD, Madhusudhan Reddy G (1999) Microstructural refinement of weld fusion zones in $\alpha-\beta$ titanium alloys using pulsed current welding. Mater Sci Eng A 262(1-2):88-100

16. Yung WKC, Ralph B, Lee WB, Fenn R (1997) An investigation into welding parameters affecting the tensile properties of titanium welds. J Mater Process Technol 63(96):759-764

17. Baeslack WA III, Becker DW, Froes FH (1984) Advances in titanium alloy welding metallurgy. J Miner Met Mater Soc 36(5):46-58

18. Weman K (2012) Welding processes handbook, 2nd ed. Woodhead Publishing Cambridge, UK

19. Otani T (2007) Titanium welding technology Nippon Steel Technical Report No. 95

20. Lathabai S, Jarvis BL, Barton KJ (2001) Comparison of keyhole and conventional gas tungsten arc welds in commercially pure titanium. Mater Sci Eng A 299(1-2):81-93

21. Yunlian Q, Ju D, Quan H, Liying Z (2000) Electron beam welding, laser beam welding and gas tungsten arc welding of titanium sheet. Mater Sci Eng A 280(1):177-181

22. Akman E, Demir A, Canel T, Sinmazçelik T (2009) Laser welding of Ti6Al4V titanium alloys. J Mater Process Technol 209(8):3705-3713

23. Gao X-L, Zhang L-J, Liu J, Zhang J-X (2013) A comparative study of pulsed Nd:YAG laser welding and TIG welding of thin Ti6Al4V titanium alloy plate. Mater Sci Eng A 559:14-21

24. Wang $S, W u X(2012)$ Investigation on the microstructure and mechanical properties of Ti-6Al-4V alloy joints with electron beam welding. Mater Des 36:663-670

25. Mavromihales M, Mason J, Weston W (2003) A case of reverse engineering for the manufacture of wide chord fan blades (WCFB) used in Rolls Royce aero engines. J Mater Process Technol 134(3):279-286

26. Oliveira JP, Panton B, Zeng Z, Andrei CM, Zhou Y, Miranda RM, Fernandes FMB (2016) Laser joining of NiTi to Ti6Al4V using a Niobium interlayer. Acta Mater 105:9-15

27. Cai X, Sun D, Li H, Meng C, Wang L, Shen C Dissimilar joining of TiAl alloy and Ni-based superalloy by laser welding technology using $\mathrm{V} / \mathrm{Cu}$ composite interlayer. Opt Laser Technol 111, 2019(2018):205-213

28. Mo D, Wang Y, Fang Y, Song T, Jiang X (2018) Influence of welding speed on the microstructure and mechanical properties of electron beam-welded. Metals (Basel):8, 10

29. Kang S-JL (2004) Sintering -densification, grain growth and microstructure, 1st ed. Elsevier Science

30. Djohari H, Martínez-Herrera JI, Derby JJ (2009) Transport mechanisms and densification during sintering: I. Viscous flow versus vacancy diffusion. Chem Eng Sci 64(17):3799-3809

31. Davies PD (2014) Fatigue characterisation of Novell titanium alloys for future aero engine components. Swansea University

32. Humphreys FJ, Hatherly M (2004) Recrystallization and related annealing phenomena, 2nd edn. ELSEVIER Ltd, Oxford

33. Lü G, Peters M, Gysler A (1984) Influence of texture on fatigue properties of Ti-6Al-4V. Metall Mater Trans A 15(8):1597-1605

34. Lutjering G (1998) Influence of processing on microstructue and mechanical properties of alpha \& beta titanium alloys. Mater Sci Eng A243:32-45

35. Thomas M, Hewitt J, Bache M, Thomas R, Garratt P, and Kosaka Y (2016) Determination and analysis of the cyclic and dwell fatigue performance of Timetal ${ }^{\circledR}$ 575, in Proceedings of the 13th world conference on titanium, pp. 979-984

Publisher's note Springer Nature remains neutral with regard to jurisdictional claims in published maps and institutional affiliations. 